\title{
Deficiency of sex hormones does not affect 17 -ß3-estradiol-induced coronary vasodilation in the isolated rat heart
}

\author{
R.L. Santos, J.T. Lima, W.N. Rouver and M.R. Moysés \\ Departamento de Ciências Fisiológicas Centro de Ciências da Saúde, Universidade Federal do Espírito Santo, Vitória, ES, Brasil
}

\begin{abstract}
The relaxation of coronary arteries by estrogens in the coronary vascular beds of naive and hypertensive rats has been well described. However, little is known about this action in gonadectomized rats. We investigated the effect of 17-ß-estradiol (E2) in coronary arteries from gonadectomized rats, as well as the contributions of endothelium-derived factors and potassium channels. Eight-week-old female and male Wistar rats weighing 220-300 g were divided into sham-operated and gonadectomized groups ( $n=9-12$ animals per group). The baseline coronary perfusion pressure (CPP) was determined, and the vasoactive effects of $10 \mu \mathrm{M} \mathrm{E2}$ were assessed by bolus administration before and after endothelium denudation or by perfusion with $\mathrm{N}^{\mathrm{G}}$-nitro-L-arginine methyl ester (L-NAME), indomethacin, clotrimazole, L-NAME plus indomethacin, L-NAME plus clotrimazole or tetraethylammonium (TEA). The CPP differed significantly between the female and sham-operated male animals. Gonadectomy reduced the CPP only in female rats. Differences in E2-induced relaxation were observed between the female and male animals, but male castration did not alter this response. For both sexes, the relaxation response to E2 was, at least partly, endothelium-dependent. The response to E2 was reduced only in the sham-operated female rats treated with L-NAME. However, in the presence of indomethacin, clotrimazole, L-NAME plus indomethacin or L-NAME plus clotrimazole, or TEA, the E2 response was significantly reduced in all groups. These results highlight the importance of prostacyclin, endothelium-derived hyperpolarizing factor, and potassium channels in the relaxation response of coronary arteries to E2 in all groups, whereas nitric oxide may have had an important role only in the sham-operated female group.
\end{abstract}

Key words: Gonadectomy; Estrogen; Vasodilation; Coronary arteries

\section{Introduction}

Sex differences in the incidence of cardiovascular diseases (CVDs), such as hypertension and coronary artery disease, have been reported. CVDs are more common in men than in women, in the age group 30 to 50 years (1). Additionally, the risk of CVDs is greater in postmenopausal women compared to premenopausal women, which suggests that there are vascular benefits of estrogens and that the decrease in plasma levels of estrogens during menopause may contribute to this risk $(2,3)$. However, the roles of female sex steroids in mediating or protecting against CVDs are controversial (4).

The protective effects of estrogens are mainly attributed to their direct actions on blood vessels (5), physiologically stimulating the release of endotheliumderived factors $(6,7)$. Estrogens may also play an important role in regulating ion channels in vascular smooth muscle cells (8). Many other beneficial vascular effects of estrogens have also been suggested, including anti-proliferative effects on vascular smooth muscle cells (9), and composition modifications of circulating lipoproteins (e.g., decrease low-density lipoprotein cholesterol and increase high-density lipoprotein cholesterol) (10). Additionally, estrogens directly inhibit cardiovascular L-type $\mathrm{Ca}^{2+}$ channels (11).

Estradiol may indirectly affect both the vascular tone and the vasoreactivity to different stimulators of relaxation, such as serotonin (12) or bradykinin (13). Estrogens can have rapid effects on vascular cells by activating nitric oxide synthase (NOS) in a non-genomic manner (14). Estrogens can also have long-term effects, due in part to increases in the expression of genes encoding NOS (15). Nitric oxide (NO) is produced in the vascular endothelial cells through the activity of constitutive endothelial NO synthase (eNOS). Nevertheless, estrogens might modulate NO synthesis by up-regulating the expression of antioxidants and longevity-related genes (16), and by

Correspondence: R.L. Santos: <rogerlyrio@hotmail.com> 
regulating the expression of genes encoding essential co-factors or enzymes that increase eNOS activity by post-translational modification (17).

In addition to its effects on $\mathrm{NO}$, estrogens can enhance the release of prostacyclin $\left(\mathrm{PGI}_{2}\right)$ derived from the metabolism of arachidonic acid (i.e., from the cyclooxygenase pathway) through activation of the gene encoding cyclooxygenase in endothelial cells (18). Also, estrogens increase the release of endothelium-derived hyperpolarizing factor (EDHF) from endothelial cells (19). Evidence reported by a number of studies using arteries from many species indicates that epoxyeicosatrienoic acids (EETs) act as EDHFs, at least in coronary arteries $(20,21)$.

In coronary arteries, estrogens stimulate the release of three distinct endothelium-derived relaxation compounds: $\mathrm{NO}, \mathrm{PGI}_{2}$ and EDHF. Our previous studies have revealed the relationships between estrogens and these endotheliumderived factors in the coronary vascular bed in normotensive (6) as well as in hypertensive rats (22). However, little is known about these relationships in the coronary vascular bed of gonadectomized rats or the interaction between estrogens and potassium channels in that group of animals. In addition, although the effects of estrogen deficiency have been previously analyzed in other vascular beds (23), little is known about the effects of this deficiency in the coronary vascular bed when using estradiol as an agonist to stimulate a relaxation response. Indeed, sex-dependent functional effects have not been studied in the coronary circulation of gonadectomized rats. Systematically assessing the sexdependent functional effects and determining the mechanisms accounting for sex differences in coronary vascular function would be valuable for better understanding the functional basis of sex differences in vascular disease. Understanding sex differences would also provide a foundation for the potential development of sex-dependent diagnostic and treatment strategies. Therefore, the present study was designed to test the hypothesis that 17-3-estradiol (E2) induces coronary vasodilation in isolated perfused hearts from gonadectomized male and female rats and to assess the relative effects of the endothelium and its relaxation factors on the activity of E2. The role of potassium channels in this process was also examined.

\section{Material and Methods}

\section{Animals}

Eight-week-old female and male Wistar rats $(n=9-12$ animals per group), weighing 220-300 g were obtained from the University's animal facility. All procedures were approved by the Institutional Ethics Committee for Animal Care and Use of the Universidade Federal do Espírito Santo under protocol \#029/2011. The experiments were conducted in accordance with the Guide for the Care and Use of Laboratory Animals (24), and efforts were made to minimize the animals' suffering. The animals were kept in collective cages with free access to water and standard rat chow (Purina Labina ${ }^{\circledR}$, Brazil) under controlled temperature $\left(22-24^{\circ} \mathrm{C}\right)$ and humidity $(40-60 \%)$ conditions with a 12-12-h light-dark cycle. The female and male rats were divided into sham-operated and gonadectomized groups.

\section{Gonadectomy}

Gonadectomy was performed on male and female rats using sodium pentobarbital (50 mg/kg, ip, Sigma, USA) anesthesia. In females, bilateral dorsolateral incisions were made through the skin, and the underlying muscle was dissected to locate the ovary and fallopian tube. The tube was ligated with a suture line, and the ovary removed. The muscle and skin were then sutured with an absorbable suture. In males, a small incision was created in the posterior tip of each scrotal sac, the spermatic cord was tied, and the testes were removed. The incision was closed with 4.0 silk sutures, and the animals were allowed to recover. After surgery, all animals received an antibiotic injection $(2.5 \%$ norfloxacin, $0.1 \mathrm{~mL}$, im, Chemitec, Brazil). All animals underwent surgery on the same day, and the protocols were initiated after 7 days of recovery (25). Sham-operated rats were incised and sutured, but the ovary or testes were left intact.

\section{Isolated heart preparation (modified Langendorff method)}

The experiments were performed on isolated perfused hearts from female and male Wistar rats. The animals were anesthetized with sodium pentobarbital (50 mg/kg, ip) and injected $s c$ with heparin $(100 \mathrm{U} / \mathrm{kg})$. Fifteen minutes after heparin injection, rats were sacrificed, and hearts were excised (26). Analyses of the coronary vascular bed were performed on whole hearts using the Langendorff preparation as previously described (22). Briefly, using a Langendorff apparatus (Hugo Sachs Electronics, Germany), the isolated hearts were perfused with a modified Krebs solution containing the following: $120 \mathrm{mM} \mathrm{NaCl}, 1.26 \mathrm{mM}$ $\mathrm{CaCl}_{2} \cdot 2 \mathrm{H}_{2} \mathrm{O}, 5.4 \mathrm{mM} \mathrm{KCl}, 2.5 \mathrm{mM} \mathrm{MgSO}_{4} \cdot 7 \mathrm{H}_{2} \mathrm{O}, 2 \mathrm{mM}$ $\mathrm{NaH}_{2} \mathrm{PO}_{4} \cdot \mathrm{H}_{2} \mathrm{O}, 27 \mathrm{mM} \mathrm{NaHCO} 3,1.2 \mathrm{mM} \mathrm{Na}_{2} \mathrm{SO}_{4}, 0.03 \mathrm{mM}$ EDTA, and $11.0 \mathrm{mM}$ glucose. The Krebs solution was equilibrated with a mixture of $95 \%$ oxygen and $5 \%$ carbon dioxide at a controlled pressure of $100 \mathrm{mmHg}$ to bring the $\mathrm{pH}$ to 7.4. The hearts were perfused at a rate of $10 \mathrm{~mL} / \mathrm{min}$ with a peristaltic pump (MS-Reglo 4 channels, Hugo Sachs Electronics, Germany) and were kept at $37^{\circ} \mathrm{C}$. A fluid-filled balloon was introduced into the left ventricle through a steel cannula connected to a P23Db Statham pressure transducer (Hugo Sachs Electronics) to measure the isovolumetric cardiac force. The balloon was pressurized by a spindle syringe until it reached a preload of $10 \mathrm{mmHg}$.

The coronary perfusion pressure (CPP) was monitored with the P23Db Statham transducer connected to a sidearm of an aortic perfusion catheter. As an inclusion criterion for the heart preparations, only hearts that showed stabilization of CPP between 60 and $120 \mathrm{mmHg}$ 
for both sexes were used, because a CPP of less than $60 \mathrm{mmHg}$ indicated that an error likely occurred during heart preparation, and a CPP of greater than $120 \mathrm{mmHg}$ prevented stabilization of the preparation. Once the preparation was stabilized, the baseline CPP was measured approximately $40 \mathrm{~min}$ later, and the vasoactive effects of E2 $(10 \mu \mathrm{M})$ were assessed by bolus infusion of sodium deoxycholate $(0.25 \mu \mathrm{M}$ deoxycholic acid for $10 \mathrm{~min}$ ) before and after endothelial denudation or by perfusion with $\mathrm{N}^{\mathrm{G}}$-nitro-L-arginine methyl ester (L-NAME, $100 \mu \mathrm{M}$, an inhibitor of NOS), indomethacin [2.8 $\mu \mathrm{M}$, an inhibitor of cyclooxygenase (COX)], clotrimazole [0.75 $\mu \mathrm{M}$, an inhibitor of cytochrome P450 (CYP)], L-NAME (100 $\mu \mathrm{M})$ plus indomethacin $(2.8 \mu \mathrm{M})$, L-NAME $(100 \mu \mathrm{M})$ plus clotrimazole $(0.75 \mu \mathrm{M})$ or tetraethylammonium (TEA, $4 \mathrm{mM})$. We performed chemical removal of the endothelium by bolus infusion of sodium deoxycholate. The removal efficiency was confirmed by a significant reduction in the vasodilatory response to $0.5 \mu \mathrm{M}$ bradykinin. In addition, we used sodium nitrite $(0.1 \mathrm{mM})$ to confirm the ability of vascular smooth muscle to respond to a NO donor. All inhibitors were perfused for at least 20 min until the bolus injection of E2 was repeated.

\section{Drugs and chemicals}

Sodium nitrite was obtained from Ecibra (Brazil), and E2, bradykinin, L-NAME, COX, clotrimazole, tetraethylammonium, and sodium deoxycholate were purchased from Sigma Chemical Co. (USA). E2 was separately prepared as a stock solution in absolute ethanol and was then diluted in absolute ethanol to the concentration needed for each experiment. E2 was added to the physiological medium at each concentration with a final volume of $0.1 \%$ absolute ethanol (v:v).

\section{Statistical analysis}

Data are reported as means \pm SE. A paired Student's $t$-test was used to analyze the baseline CPPs before and after treatment with each inhibitor. Data on the relaxation response to E2 were analyzed by two-way analysis of variance (ANOVA) and Tukey's post hoc test. Statistical significance was set at $P<0.05$.

\section{Results}

The baseline CPP was significantly higher in female rats than in sham-operated male rats (Figure 1). Castration had no effect on the baseline CPP of hearts from male rats. In contrast, ovariectomy caused a significant reduction in the baseline CPP of hearts from female rats (Figure 1).

The bolus injection of E2 $(10 \mu \mathrm{M})$ elicited a transient relaxation response in all groups (Figure $2 \mathrm{~A})$. Differences in E2-induced relaxation were detected between the female and sham-operated male rats $(-15 \pm 1$ vs $-11 \pm 1 \%$, respectively, $\mathrm{P}<0.05)$. Similarly, we found differences in the


Figure 1. Baseline coronary perfusion pressure (CPP) values in isolated hearts obtained from sham-operated and gonadectomized female and male rats (n=44 for each group) before $(A)$ and after $(B)$ endothelial removal. Data are reported as means \pm SE. ${ }^{*} \mathrm{P}<0.05$ compared to the sham-operated females. ${ }^{\#} \mathrm{P}<0.05$ compared to the gonadectomized females. ${ }^{+} \mathrm{P}<0.05$ compared to the same group under control conditions (before endothelium removal, shown in panel $A$ ) (two-way ANOVA and Tukey's post hoc test).

relaxation response between the female and male gonadectomized rats $(-14 \pm 1$ vs $-10 \pm 1 \%$, respectively, $\mathrm{P}<0.05)$ (Figure 2A). However, gonadectomy did not alter E2induced vasodilation in either sex. The E2 response was reduced in all animals after removal of the endothelium (Figure 2B), including female and sham-operated male rats ( $-15 \pm 1$ to $-4 \pm 1 \%$ and $-11 \pm 1$ to $-5 \pm 1 \%$, respectively) and female and male gonadectomized rats $(-14 \pm 1$ to $-4 \pm 1 \%$ and $-10 \pm 1$ to $-1 \pm 1 \%$, respectively). The E2 response was not blocked in any group, indicating the existence of an indirect (endothelium-mediated) mechanism, as well as the direct action of E2 on vascular smooth muscle cells. Treatment with sodium deoxycholate significantly reduced the vasodilatory response to $0.5 \mu \mathrm{M}$ bradykinin in all groups (Figure $3 \mathrm{~A}$ and $\mathrm{B}$ ), while the vasodilatory response to $0.1 \mathrm{mM}$ sodium nitrite (a NO donor) remained unchanged (Figure $3 \mathrm{C}$ and $\mathrm{D}$ ). These results suggest that after treatment with sodium deoxycholate, the ability of coronary endothelial cells to produce relaxation factors is reduced, whereas the ability of vascular smooth muscle cells to respond to sodium nitrite (a NO donor) remains unchanged. The concentration of sodium deoxycholate used in this study is suitable for the 

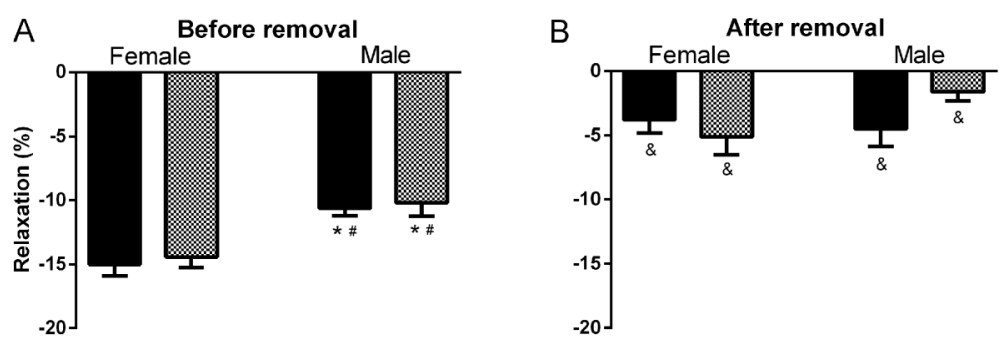

Figure 2. Relaxation responses to 17- $\beta$-estradio in the coronary vascular beds of sham-operated and gonadectomized female and male rats before $(A, \mathrm{n}=28)$ and after endothelium removal $(B, \mathrm{n}=10)$ or perfusion with $\mathrm{N}^{\mathrm{G}}$-nitro-L-arginine methyl ester (L-NAME) $(C, n=12)$, indomethacin $(D, \mathrm{n}=10)$, clotrimazole $(E, \mathrm{n}=9)$, L-NAME plus indomethacin $(F, n=10)$, L-NAME plus clotrimazole (CLOT; $G, \mathrm{n}=9$ ), or tetraethylammonium (TEA; $H, \mathrm{n}=9$ ). Data are reported as means $\pm \mathrm{SE}$. ${ }^{*} \mathrm{P}<0.05$ compared to the sham-operated females, ${ }^{\#} \mathrm{P}<0.05$ compared to the gonadectomized females, and ${ }^{\circledR} P<0.05$ compared to the same
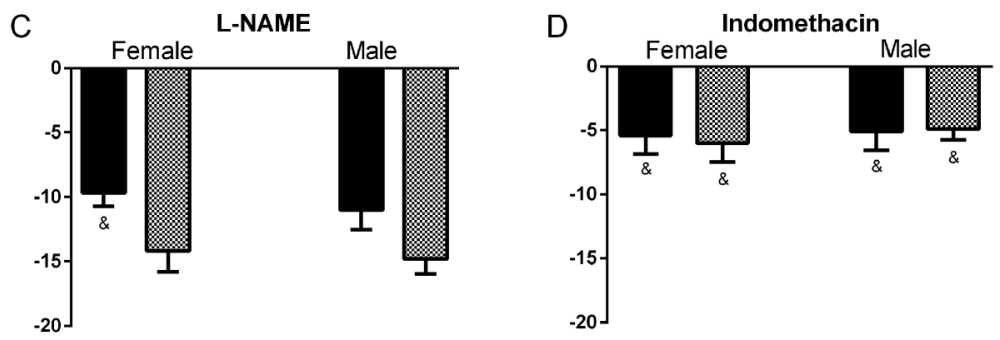
group under control conditions (before endothelium removal, $A$ ) (two-way ANOVA and Tukey's post hoc test).
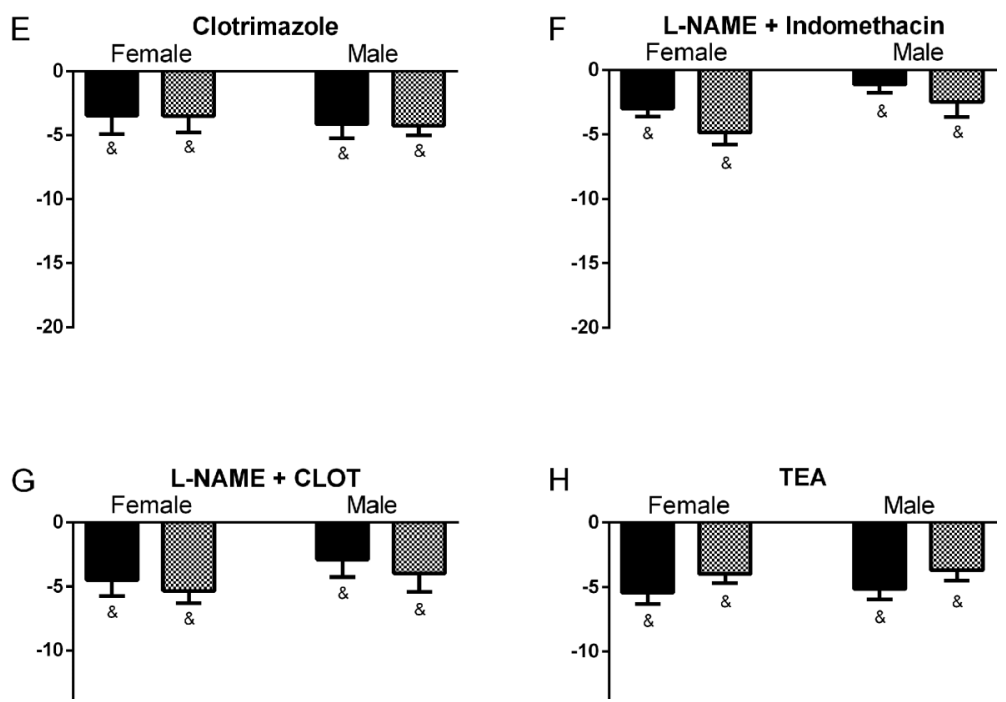

removal of endothelial cells, as shown in previous studies conducted by our group $(22,27)$.

In the presence of a NOS inhibitor (L-NAME, $100 \mu \mathrm{M})$, the dilation response to $E 2$ was significantly reduced only in the sham-operated female group $(-15 \pm 1$ to $-10 \pm 1 \%$, Figure 2C). Nevertheless, in the presence of indomethacin (Figure 2D), the E2 response was reduced in female and sham-operated male rats $(-15 \pm 1$ to $-7 \pm 2 \%$ and $-11 \pm 1$ to $-5 \pm 1 \%$, respectively), as well as in female and male gonadectomized rats $(-14 \pm 1$ to $-8 \pm 1 \%$ and $-10 \pm 1$ to $-5 \pm 1 \%$, respectively). Perfusion with clotrimazole (Figure $2 \mathrm{E}$ ) also reduced the $\mathrm{E} 2$ response in all animals, including the female and sham-operated male rats $(-15 \pm 1$ to $-3 \pm 1 \%$ and $-11 \pm 1$ to $-4 \pm 1 \%$, respectively) and female and male gonadectomized rats $(-14 \pm 1$ to $-3 \pm 1 \%$ and $-10 \pm 1$ to $-4 \pm 1 \%$, respectively). In addition, the combined treatment of L-NAME plus indomethacin (Figure 2F) or LNAME plus clotrimazole (Figure 2G) decreased the relaxation response in all groups. These results indicate the importance of $\mathrm{PGI}_{2}$ and EDHF in the relaxation response of coronary arteries to $\mathrm{E} 2$ in all groups. The dilation response to E2 was reduced in all groups after perfusion with $4 \mathrm{mM}$ TEA (Figure $2 \mathrm{H}$ ), indicating the importance of potassium channels in mediating the relaxation response of coronary arteries to E2. Endothelium removal elicited a significant increase in the CPP 

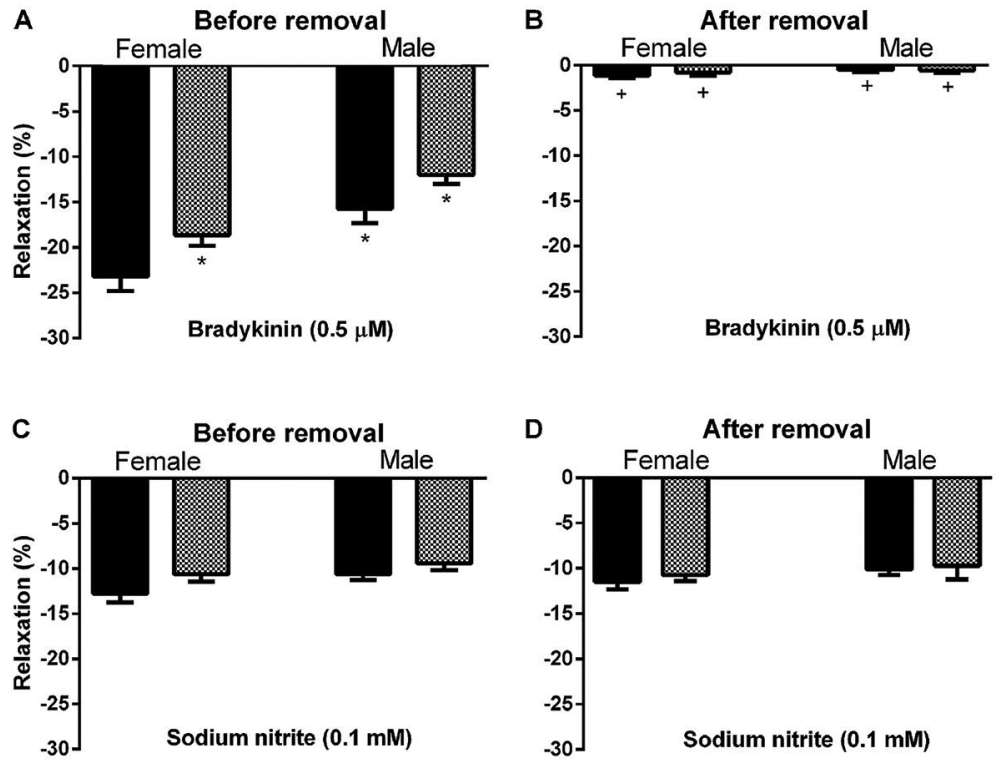

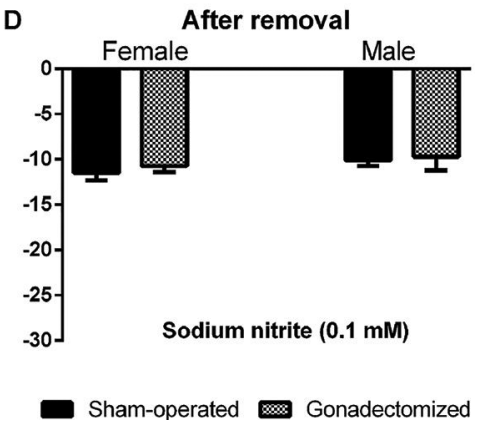

Figure 3. Relaxation responses to bradykinin $(A$ and $B)$ and sodium nitrite $(C$ and $D)$ in the coronary vascular beds of the sham-operated and gonadectomized female and male rats before and after endothelium removal. Data are reported as means $\pm S E ; n=8$ animals in each group. ${ }^{*} \mathrm{P}<0.05$ compared to the sham-operated females, and ${ }^{+} \mathrm{P}<0.05$ compared to the same group under control conditions (before endothelium removal, $A$ ) (two-way ANOVA and Tukey's post hoc test).
(Figure 1), which demonstrates the important role of the endothelium in regulating coronary tone. The significant contribution of basal $\mathrm{NO}$ and $\mathrm{PGI}_{2}$ release to the maintenance of coronary tone is illustrated by the marked increase in the CPP observed following the inhibition of $\mathrm{NO}$ synthesis or $\mathrm{PGI}_{2}$ synthesis (Table 1). Obviously, we also found differences in the CPP in both groups after the combined treatment of L-NAME plus indomethacin, and the combined treatment of L-NAME plus clotrimazole (data not shown).

\section{Discussion}

The main findings of the present study were that E2 was able to elicit a transient relaxation response in rat coronary arteries from sham-operated and gonadectomized female and male rats and that the mechanisms involved in this response were similar among the groups. The relaxation effect of E2 in the sham-operated and gonadectomized rats was mediated, at least in part, by the opening of potassium channels and subsequent actions of endothelial factors.

Our first observation was that the basal CPP was significantly higher in hearts from sham-operated female rats than in those from sham-operated male rats. These observations are similar to those of our previous studies of normotensive and hypertensive rats $(6,22)$.

We found that gonadectomy reduced the CPP only in the females, suggesting a role for female sex hormones in the maintenance of coronary tone. Indeed, after treatment of the ovariectomized rats with $\mathrm{E} 2$, the CPP values became similar to those of the sham-operated animals (12). Sex hormones, mainly estrogens, may contribute

Table 1. Coronary perfusion pressure (CPP) of isolated hearts before and after perfusion with $100 \mu \mathrm{M} \mathrm{N}^{\mathrm{G}}$-nitro-L-arginine methyl ester (L-NAME), $2.8 \mu \mathrm{M}$ indomethacin (INDO) or $0.75 \mu \mathrm{M}$ clotrimazole (CLOT).

\begin{tabular}{|c|c|c|c|c|c|c|c|c|c|}
\hline \multirow{2}{*}{$\begin{array}{l}\text { Treatment } \\
\text { CPP }(\mathrm{mmHg})\end{array}$} & \multicolumn{3}{|c|}{ L-NAME } & \multicolumn{3}{|c|}{ INDO } & \multicolumn{3}{|c|}{ CLOT } \\
\hline & $\mathrm{n}$ & Before & After & $\mathrm{n}$ & Before & After & $\mathrm{n}$ & Before & After \\
\hline \multicolumn{10}{|l|}{ Sham-operated } \\
\hline Female & 11 & $105 \pm 6$ & $174 \pm 8^{*}$ & 11 & $104 \pm 4$ & $127 \pm 6^{*}$ & 9 & $103 \pm 6$ & $105 \pm 6$ \\
\hline Male & 12 & $87 \pm 4$ & $141 \pm 8^{*}$ & 11 & $86 \pm 4$ & $105 \pm 5^{\star}$ & 8 & $72 \pm 2$ & $75 \pm 3$ \\
\hline \multicolumn{10}{|c|}{ Gonadectomized } \\
\hline Female & 14 & $91 \pm 5$ & $161 \pm 6^{*}$ & 13 & $89 \pm 3$ & $107 \pm 5^{*}$ & 8 & $90 \pm 4$ & $100 \pm 6$ \\
\hline Male & 11 & $71 \pm 3$ & $122 \pm 11^{*}$ & 8 & $78 \pm 4$ & $89 \pm 6$ & 8 & $85 \pm 4$ & $94 \pm 5$ \\
\hline
\end{tabular}

Data are reported as means $\pm \mathrm{SE}$ in $\mathrm{mmHg} .{ }^{*} \mathrm{P}<0.05$ compared to the same group before perfusion with different inhibitors (paired Student's $t$-test). 
indirectly to gender differences in the cardiovascular system by acting on components of the renin-angiotensin system that may play roles in the control of coronary tone (28). The functional significance of the higher CPP in females is unclear. Perhaps this increased CPP allows for greater vasodilation when the supply of oxygen and/or nutrients becomes reduced. Notably, even after gonadectomy, these differences in the CPP continued to exist between females and males, perhaps because the effects of estrogens on the renin-angiotensin system were not completely lost 14 days after gonadectomy. FigueroaValverde et al. (11) have suggested that the effects of E2 on perfusion pressure and vascular coronary tone involve the activation of L-type calcium channels through a non-genomic molecular mechanism. Further experiments are necessary to elucidate the basis of sex hormone-dependent elevation in the CPP and to determine whether this elevation has a role in the cardioprotective effects of estrogens observed in female rats.

Although we found differences in CPP between the female and male rats, our main aim was to study the relaxation response of coronary arteries to E2 in isolated perfused hearts. Our results showed that administration of E2 directly into coronary arteries from sham-operated and gonadectomized rats caused rapid vasodilation by stimulating endothelial factors ( $\mathrm{NO}, \mathrm{PGI}_{2}$ and $\mathrm{EDHF}$ ) production and opening potassium channels in all groups. This rapid effect of estrogens on blood vessel walls is believed to occur in the absence of any changes in gene expression and is likely a result of "non-genomic" mechanisms or "extra-nuclear" pathways (29).

Differences in E2-induced relaxation were observed between the female and male rats, suggesting that the ability of E2 to produce a relaxation effect in vitro is at least partly dependent on sex. These results corroborate those of our previous studies $(6,12)$. In fact, even after the deprivation of female sex hormones by gonadectomy, E2induced relaxation was greater in female rats compared with the sham-operated or gonadectomized male rats.

Our data demonstrated an acute relaxation response of rat coronary microcirculation to E2 in all groups. The relaxation response is at least partly endothelium-dependent, but E2 may also have a direct action on vascular smooth muscle cells that can be observed at higher E2 concentrations $(\cong 10 \mu \mathrm{M})$. The concentration of E2 at which effects were observed was higher than its normal circulating levels (typically $10^{-8}$ to $10^{-10} \mathrm{M}$ ). It is known that high concentrations of hormones are required for some short-term membrane effects in vitro. In addition, it is possible that chronic exposure of the coronary vascular bed to physiological levels of E2 in vivo may have an effect similar to that of supraphysiological levels in vitro.

Our results showed that E2 stimulated the release of $\mathrm{PGI}_{2}$ and EDHF, and activated potassium channels in all groups of normotensive rats. It also stimulated the release of $\mathrm{NO}$ in the sham-operated female rats. However, in the coronary arteries of hypertensive rats, the mechanisms involved in E2-induced relaxation differ between the sexes; i.e., NO, EDHF and potassium channels may have the most important roles as mediators of the relaxation response of E2 in females, whereas $\mathrm{NO}$ and potassium channels may have the most important roles in males (22). Indeed, E2 is an effective vasodilating agent that has been demonstrated to elicit full relaxation in various isolated blood vessel preparations, including rabbit coronary arteries (29). However, little is known about the roles of $\mathrm{NO}$, EDHF, potassium channels, and $\mathrm{PGI}_{2}$ in the $\mathrm{E} 2-$ induced relaxation of coronary arteries in isolated hearts from gonadectomized female and male rats.

With the exception of the sham-operated female group, our results demonstrated that the relaxation response to E2 was not significantly diminished following NOS inhibition, indicating that $\mathrm{NO}$ does not play an important role as a mediator of the E2 action in coronary arteries of gonadectomized animals or of sham-operated male rats. The endogenous estrogen $\mathrm{E} 2$, is able to enhance vascular NO bioavailability by chronically increasing eNOS expression and acutely stimulating eNOS activity through estrogen receptor-dependent signal transduction, most notably involving the phosphatidylinositol 3-kinase/Akt/eNOS pathway in endothelial cells (14). However, after ovariectomy, these stimulatory effects of E2 on eNOS could be lost, which could explain why $\mathrm{NO}$ is not a mediator of estrogen-induced relaxation in the coronary arteries of gonadectomized rats and why only premenopausal women are typically protected from CVD. Under conditions in which the synthesis or action of NO is reduced, such as in atherosclerosis, hypercholesterolemia, or ischemia, $\mathrm{PGI}_{2}$ and/or EDHF release evoked by local mediators or pulsatile stretching may be a crucial compensatory or reserve mechanism for the maintenance of myocardial blood flow (30).

Some steroids have been found to exert effects on vascular reactivity via the synthesis and secretion of prostaglandins (31). Notwithstanding, sex differences in indomethacin-sensitive vascular relaxation have been found to be related to differences in the levels of COX products (32). More specifically, E2 induces cyclooxygenase-2 activity and rapidly stimulates secretion of the prostaglandins $\mathrm{PGI}_{2}$ and $\mathrm{PGE}_{2}$ in endothelial cells (33). Indeed, in our study, the relaxation response to E2 was significantly diminished following cyclooxygenase inhibition in all groups. Alternatively, in hypertensive animals, COX inhibition has been reported to have no effect on estrogen-induced vasodilation (22). Therefore, the involvement of COX metabolites in the dilation response to E2 appears to vary depending on the animal model studied.

The identity of EDHF has remained elusive to date. Several mechanisms contribute to the EDHF phenomenon, and the contribution to vasodilatation varies depending on the species and vascular bed studied (34) and the agonist used to stimulate the endothelium (35). EDHF candidates include hydrogen peroxide $(36,37)$, potassium ions $(38)$, 
C-type natriuretic peptide (39), electrical communication through myoendothelial gap junctions (40), and a cytochrome P450-derived arachidonic acid metabolite. In our study, clotrimazole inhibited E2-induced vasodilation in all groups, providing evidence in support of the hypothesis that arachidonic acid metabolites, namely EETs, may be the EDHFs in coronary microcirculation. In fact, the EDHF may be a cytochrome P450-derived arachidonic acid metabolite in coronary microcirculation (21).

To our knowledge, this study is the first to demonstrate that EDHF participates in the acute relaxation response of coronary arteries to E2 in isolated perfused hearts from gonadectomized female and male rats. In addition, in the presence of L-NAME plus clotrimazole, the response of coronary arteries to E2 was significantly reduced in all groups, indicating the importance of EDHF, but not NO, in the dilation response to $E 2$, as this response was not reduced by L-NAME alone in any of the rats except for those in the sham-operated female group.

We used TEA to assess the contribution of potassium channels to E2-induced relaxation. In the presence of TEA, both the potency and reactivity of E2 were reduced, thereby implicating $\mathrm{K}^{+}$channels in the relaxation response of coronary arteries to E2 in sham-operated and gonadectomized female and male rats. A preliminary study conducted by our group also demonstrated the involvement of $\mathrm{K}^{+}$ channels in estrogen-induced vasodilation, but that study was performed on hypertensive rats (22). Thus, potassium channels seem to mediate the dilatory response to E2 in both normotensive and hypertensive rats.

In our study, the role of the endothelium in the control of coronary tone was demonstrated by the significant increase in CPP after endothelial denudation. The contribution of basal and shear stress-dependent $\mathrm{NO}$ and $\mathrm{PGI}_{2}$ release to

\section{References}

1. Smiley DA, Khalil RA. Estrogenic compounds, estrogen receptors and vascular cell signaling in the aging blood vessels. Curr Med Chem 2009; 16: 1863-1887. doi: 10.2174/ 092986709788186093.

2. Orshal JM, Khalil RA. Gender, sex hormones, and vascular tone. Am J Physiol Regul Integr Comp Physiol 2004; 286: R233-R249. doi: 10.1152/ajpregu.00338.2003.

3. Koledova VV, Khali RA. Sex hormone replacement therapy and modulation of vascular function in cardiovascular disease. Expert Rev Cardiovasc Ther 2007; 5: 777-789. doi: 10.1586/ 14779072.5.4.777.

4. Hsia J, Langer RD, Manson JE, Kuller L, Johnson KC, Hendrix $\mathrm{SL}$, et al. Conjugated equine estrogens and coronary heart disease: the Women's Health Initiative. Arch Intern Med 2006; 166: 357-365. doi: 10.1001/archinte.166.3.357.

5. Mendelsohn ME, Karas RH. Molecular and cellular basis of cardiovascular gender differences. Science 2005; 308: 1583-1587. doi: 10.1126/science.1112062.

6. Santos RL, Abreu GR, Bissoli NS, Moyses MR. Endothelial mediators of 17 beta-estradiol-induced coronary vasodilation the maintenance of coronary tone was demonstrated by the marked increase in CPP observed following the inhibition of $\mathrm{NO}$ or $\mathrm{PGI}_{2}$ synthesis, suggesting that the basal release of NOS or COX products, i.e., $\mathrm{NO}$ or $\mathrm{PGI}_{2}$, is important in influencing the tone of the coronary arteries. Indeed, to the native resistance vasculature, prostaglandin vasodilators are very important determinants of coronary collateral vessel tone, and the blocking of cyclooxygenase activity reduces collateral perfusion (21). However, cytochrome P450 inhibition did not affect the CPP under control conditions, suggesting that the basal release of cytochrome P450 products, i.e., EET/EDHF, is too low to significantly influence the tone of the coronary arteries.

Therefore, we conclude that the relaxation effect of E2 in rat coronary arteries was mediated by an indirect (endothelium-mediated) mechanism as well as a direct action on vascular smooth muscle cells. Prostacyclin, EDHF, and potassium channels may have the most important roles as mediators of the relaxation response of E2 in gonadectomized and sham-operated male rats, whereas NO, EDHF, $\mathrm{PGI}_{2}$ and potassium channels may have important roles in sham-operated female rats. In addition, the significant contribution of basal $\mathrm{NO}$ and $\mathrm{PGI}_{2}$ release has been demonstrated by the marked increase in coronary perfusion pressure. The characterization of these mechanisms could lead to a better understanding of menopausal symptoms and perhaps to the development of improved therapeutic strategies.

\section{Acknowledgments}

This work was supported by grants from the FAPES (\#54687578/2011), CNPq (\#55262312011-3) and UFES (\#PIBIC 2011-12).

in the isolated rat heart. Braz $J$ Med Biol Res 2004; 37: 569-575. doi: 10.1590/S0100-879X2004000400014.

7. dos Santos RL, da Silva FB, Ribeiro RF Jr, Stefanon I. Sex hormones in the cardiovascular system. Horm Mol Biol Clin Investig 2014; 18: 89-103. doi: 10.1515/hmbci-2013-0048.

8. Han G, Ma H, Chintala R, Miyake K, Fulton DJ, Barman SA, et al. Nongenomic, endothelium-independent effects of estrogen on human coronary smooth muscle are mediated by type I (neuronal) NOS and PI3-kinase-Akt signaling. Am J Physiol Heart Circ Physiol 2007; 293: H314-H321. doi: 10.1152/ajpheart.01342.2006.

9. Odenlund M, Ekblad E, Nilsson BO. Stimulation of oestrogen receptor-expressing endothelial cells with oestrogen reduces proliferation of cocultured vascular smooth muscle cells. Clin Exp Pharmacol Physiol 2008; 35: 245-248. doi: 10.1111/j.1440-1681.2007.04870.x.

10. Kilic S, Yilmaz N, Erdogan G, Aydin M, Tasdemir N, Doganay $M$, et al. Effect of non-oral estrogen on risk markers for metabolic syndrome in early surgically menopausal women. Climacteric 2009; 8: 1-8. doi: 10.3109/13697130902914650. 
11. Figueroa-Valverde L, Diaz-Cedillo F, Lopez-Ramos M, GarciaCervera E, Quijano K, Cordoba J. Changes induced by estradiol-ethylenediamine derivative on perfusion pressure and coronary resistance in isolated rat heart: L-type calcium channel. Biomed Pap Med Fac Univ Palacky Olomouc Czech Repub 2011; 155: 27-32. doi: 10.5507/bp.2011.018.

12. Moyses MR, Barker LA, Cabral AM. Sex hormone modulation of serotonin-induced coronary vasodilation in isolated heart. Braz J Med Biol Res 2001; 34: 949-958. doi: 10.1590/ S0100-879X2001000700014.

13. Pretorius M, van Guilder GP, Guzman RJ, Luther JM, Brown NJ. 17Beta-estradiol increases basal but not bradykininstimulated release of active t-PA in young postmenopausal women. Hypertension 2008; 51: 1190-1196. doi: 10.1161/ HYPERTENSIONAHA.107.105627.

14. Haynes MP, Li L, Sinha D, Russell KS, Hisamoto K, Baron $\mathrm{R}$, et al. Src kinase mediates phosphatidylinositol 3-kinase/ Akt-dependent rapid endothelial nitric-oxide synthase activation by estrogen. J Biol Chem 2003; 278: 2118-2123. doi: 10.1074/jbc.M210828200.

15. Weiner CP, Lizasoain I, Baylis SA, Knowles RG, Charles IG, Moncada S. Induction of calcium-dependent nitric oxide synthases by sex hormones. Proc Natl Acad Sci U S A 1994; 91: 5212-5216.

16. Borras C, Gambini J, Gomez-Cabrera MC, Sastre J, Pallardo FV, Mann GE, et al. 17beta-oestradiol up-regulates longevity-related, antioxidant enzyme expression via the ERK1 and ERK2[MAPK]/NFkappaB cascade. Aging Cell 2005; 4: 113-118. doi: 10.1111/j.1474-9726.2005.00151.x.

17. Li L, Haynes MP, Bender JR. Plasma membrane localization and function of the estrogen receptor alpha variant (ER46) in human endothelial cells. Proc Natl Acad Sci U S A 2003; 100: 4807-4812.

18. Gibson LL, Hahner L, Osborne-Lawrence S, German Z, Wu $\mathrm{KK}$, Chambliss KL, et al. Molecular basis of estrogeninduced cyclooxygenase type 1 upregulation in endothelial cells. Circ Res 2005; 96: 518-525.

19. Burger NZ, Kuzina OY, Osol G, Gokina NI. Estrogen replacement enhances EDHF-mediated vasodilation of mesenteric and uterine resistance arteries: role of endothelial cell $\mathrm{Ca}^{2+}$. Am J Physiol Endocrinol Metab 2009; 296: E503-E512. doi: 10.1152/ajpendo.90517.2008.

20. Gauthier KM, Edwards EM, Falck JR, Reddy DS, Campbell WB. 14,15-epoxyeicosatrienoic acid represents a transferable endothelium-dependent relaxing factor in bovine coronary arteries. Hypertension 2005; 45: 666-671. doi: 10.1161/01.HYP.0000153462.06604.5d.

21. Gauthier KM, Deeter $C$, Krishna UM, Reddy YK, Bondlela M, Falck JR, et al. 14,15-Epoxyeicosa-5(Z)-enoic acid: a selective epoxyeicosatrienoic acid antagonist that inhibits endothelium-dependent hyperpolarization and relaxation in coronary arteries. Circ Res 2002; 90: 1028-1036. doi: 10.1161/01.RES.0000018162.87285.F8

22. Santos RL, Marin EB, Goncalves WL, Bissoli NS, Abreu GR, Moyses MR. Sex differences in the coronary vasodilation induced by 17 beta-oestradiol in the isolated perfused heart from spontaneously hypertensive rats. Acta Physiol 2010; 200: 203-210. doi: 10.1111/j.1748-1716.2010.02140.x.

23. Aberdeen GW, Baschat AA, Harman CR, Weiner CP, Langenberg PW, Pepe GJ, et al. Uterine and fetal blood flow indexes and fetal growth assessment after chronic estrogen suppression in the second half of baboon pregnancy. Am J Physiol Heart Circ Physiol 2010; 298: H881-H889. doi: 10.1152/ajpheart.00611.2009.

24. Institute of laboratory animal research.Commission on life sciences. National research council. The guide for the care and use of laboratory animals. 7th edn. Washington: National Academy of Sciences; 1996.

25. Claudio ER, Endlich PW, Santos RL, Moyses MR, Bissoli NS, Gouvea SA, et al. Effects of chronic swimming training and oestrogen therapy on coronary vascular reactivity and expression of antioxidant enzymes in ovariectomized rats. PLoS One 2014; 8: e64806. doi: 10.1371/journal.pone. 0064806.

26. Doring HJ. The isolated perfused heart according to Langendorff technique - function - application. Physiol Bohemoslov 1990; 39: 481-504.

27. dos Santos RL, Podratz PL, Sena GC, Filho VS, Lopes PF, Goncalves WL, et al. Tributyltin impairs the coronary vasodilation induced by 17 beta-estradiol in isolated rat heart. J Toxicol Environ Health A 2012; 75: 948-959. doi: 10.1080/15287394.2012.695231.

28. Xu X, Xiao JC, Luo LF, Wang S, Zhang JP, Huang JJ, et al. Effects of ovariectomy and $17 \mathrm{beta}$-estradiol treatment on the renin-angiotensin system, blood pressure, and endothelial ultrastructure. Int J Cardiol 2008; 130: 196-204. doi: 10.1016/ j.ijcard.2007.08.041.

29. Keung W, Chan ML, Ho EY, Vanhoutte PM, Man RY. Nongenomic activation of adenylyl cyclase and protein kinase $\mathrm{G}$ by 17 beta-estradiol in vascular smooth muscle of the rat superior mesenteric artery. Pharmacol Res 2011; 64: 509-516. doi: 10.1016/j.phrs.2011.05.010.

30. Hecker M. Endothelium-derived hyperpolarizing factor - fact or fiction? News Physiol Sci 2000; 15: 1-5.

31. Seillan C, Ody C, Russo-Marie F, Duval D. Differential effects of sex steroids on prostaglandin secretion by male and female cultured piglet endothelial cells. Prostaglandins 1983; 26: 3-12. doi: 10.1016/0090-6980(83)90069-2.

32. Anderson LC, Martin DJ, Phillips DL, Killpack KJ, Bone SE, Rahimian $R$. The influence of gender on parasympathetic vasodilatation in the submandibular gland of the rat. Exp Physiol 2006; 91: 435-444. doi: 10.1113/expphysiol.2005.032730.

33. Pedram A, Razandi M, Aitkenhead M, Hughes CC, Levin ER. Integration of the non-genomic and genomic actions of estrogen. Membrane-initiated signaling by steroid to transcription and cell biology. J Biol Chem 2002; 277: 50768-50775. doi: 10.1074/jbc.M210106200.

34. Shimokawa H, Yasutake H, Fuji K, Owada MK, Nakaike R, Fukumoto $\mathrm{Y}$, et al. The importance of the hyperpolarizing mechanism increases as the vessel size decreases in endothelium-dependent relaxations in rat mesenteric circulation. J Cardiovasc Pharmacol 1996; 28: 703-711. doi: 10.1097/00005344-199611000-00014.

35. Lenasi $H$. The role of nitric oxide- and prostacyclinindependent vasodilatation in the human cutaneous microcirculation: effect of cytochrome P450 2C9 inhibition. Clin Physiol Funct Imaging 2009; 29: 263-270. doi: 10.1111/ j.1475-097X.2009.00862.x.

36. Beny JL, von der Weid PY. Hydrogen peroxide: an endogenous smooth muscle cell hyperpolarizing factor. Biochem Biophys Res Commun 1991; 176: 378-384. doi: 10.1016/0006-291X(91)90935-Z. 
37. Matoba T, Shimokawa H, Nakashima M, Hirakawa Y, Mukai $\mathrm{Y}$, Hirano $\mathrm{K}$, et al. Hydrogen peroxide is an endotheliumderived hyperpolarizing factor in mice. J Clin Invest 2000; 106: 1521-1530. doi: 10.1006/bbrc.2001.6278.

38. Edwards G, Dora KA, Gardener MJ, Garland CJ, Weston $\mathrm{AH} . \mathrm{K}^{+}$is an endothelium-derived hyperpolarizing factor in rat arteries. Nature 1998; 396: 269-272. doi: 10.1038/ 24388.
39. Chauhan SD, Hobbs AJ, Ahluwalia A. C-type natriuretic peptide: new candidate for endothelium-derived hyperpolarising factor. Int J Biochem Cell Biol 2004; 36: 1878-1881. doi: 10.1016/j.biocel.2003.09.009.

40. Griffith TM, Chaytor AT, Edwards DH. The obligatory link: role of gap junctional communication in endotheliumdependent smooth muscle hyperpolarization. Pharmacol Res 2004; 49: 551-564. doi: 10.1016/j.phrs.2003.11.014. 